necessary, such as chromium and nickel, and these elements may be used in different proportions with a material degree of interchangeability, according to availability. Under such conditions a small proportion of molybdenum is desirable essentially to preserve higher values in resistance, when required, to the notched bar impact test and in part to reinforce the hardening properties. As the mass or section decreases, less alloy is needed, and this aspect is given quantitative guidance on alternate bases in $B S 970 / 1942$ and BS971. Thus the heavy use of alloying elements should be restricted according to mass.

The remarks so far refer to the development of strength and hardness in different degree by the processes of hardening and tempering. There are a considerable number of instances where alloys used in greater quantity produce important and entirely different characteristics. 13-30 per cent of chromium and 2-20 per cent of nickel, together with lesser amounts of other elements, are necessary to produce rust-, acid- or heat-resisting steels. Large quantities of tungsten and/or molybdenum, together with material quantities of chromium, vanadium and cobalt, are used to produce high-speed cutting steels. High percentages of manganese are necessary to produce the wear-resisting properties of the austenitic manganese steel. Many other special purpose applications could be quoted. The use of such steels, owing to their high alloy content, is being carefully watched and controlled.

The problem is a considerable one : namely, how at the present time to cater for a greatly increasing demand for steels of the necessary properties, with a changing availability and a considerable deficiency in some of the essential elements. Never has a more interesting technical situation developed, for solution by scientific and technical minds.

Autocracy in science or technology is as deadly as in the political field. In these efforts within the steel industry, our work is being advanced by the friendly and enthusiastic collaboration of many minds; the co-ordination of different points of view has resulted in, and is operating, a workable procedure. Stark efficient realism is necessarily our theme.

\section{THE TOTAL SOLAR ECLIPSE OF OCTOBER I, 1940}

$\mathrm{T}$ HE results obtained by the joint expedition of the National Geographic Society and the National Bureau of Standards to Brazil to observe the total solar eclipse of October, 1940, are given in enviable detail in a beautifully produced monograph appearing as No. 2 in the Solar Eclipse Series of Contributed Technical Papers of the National Geographic Society. The site selected by the two organizations was at Patos, a town of 10,000 inhabitants in north-east Brazil, some 160 miles from the coast. The programme included photographing the corona in monochrome and in colour; measurements of the brightness and polarization of the corona ; a spectro. graphic study of the flash- and coronal-spectra from $10,000 \mathrm{~A}$. to $3,000 \mathrm{~A}$.; measurements of sky brightness, from which the physical condition of the upper atmosphere was to be deduced; precise contact-time observations ; and radio sounding of the ionosphere for the purpose of studying the effects produced by the eclipse in the upper atmosphere. Much of the apparatus taken out was specially designed for this expedition, and it must have been an anxious time when, after a clear dawn, clouds began to form at sunrise. Occasional clear patches allowed glimpses of the narrowing crescent of the sun after first contact, but during totality (8.45 a.m. local time) the sky in the neighbourhood of the sun was completely veiled, though the clouds were thin enough to allow a view of the inner corona, and an excellent flashspectrum was obtained just after third contact. The photographic observations of the corona and the photometric measurements on the sky illumination were ruined, however, and even the radio observa. tions, though independent of the weather, were somewhat marred by a technical mishap. However, much valuable information has been derived from those parts of the programme which could be carried through, and the monograph contains seven papers on various aspects of the results.

I. C. Gardner describes the design and construction of the eclipse apparatus, the main items of which were two corona cameras, one equipped with a rotatable polarizing screen, and two slitless concavegrating spectrographs intended to record the chromospheric and coronal spectra in the ranges $3,000-$ $5,500 \mathrm{~A}$. and 5,000-10,000 A. respectively. All the apparatus was operated by vacuum or electric lines, either automatically or by push-button control, and the exposures were made on standard aeroplane $(240 \mathrm{~mm}$.) roll film. Instead of using mountings which can be adjusted for future eclipses in different latitudes, cheap welded frames were made in angleiron or steel tube, the intention being to provide the proper elevation in future by remaking the appropriate parts of the frame. Fine adjustment was provided by mounting the frames on ordinary screw jacks in concrete.

The short-wave spectrograph was operated manually when a sudden break in the clouds occurred at the end of totality, and a single first-order spectrogram $1 \mathrm{~m}$. long (dispersion 2.4 A./mm.) was secured, showing the chromospheric emission lines superposed on an over-exposed Fraunhofer spectrum. Unfortunately, a mishap to a control switch on the other spectrograph prevented a simultaneous long. wave record being obtained. A contribution by C. C. Kiess gives the results obtained by measurement of the spectrogram : wave-lengths, estimated intensities and characters, origins and term combinations are listed for nearly 1,100 chromospheric lines in the region $3,227-5,398 \mathrm{~A}$. The Balmer series is traced from $\mathrm{H} \beta=\mathrm{H}_{4}$ to $\mathrm{H}_{29}$, but there is no sign of the ionized helium line at 4,686 A.

As in all modern astrophysical work, calibration marks were impressed on the spectrograms with the view of deriving absolute intensities for the emission lines. The intensity calibration was performed by means of a standard tungsten-ribbon lamp operated at $2,917^{\circ} \mathrm{K}$. The intensity distribution in the spectrum of this lamp, as received at the focal surface of the eclipse spectrograph, was measured at $100 \mathrm{~A}$. intervals between $3,450 \mathrm{~A}$. and $5,350 \mathrm{~A}$. by R. Stair and W. W. Coblentz, the work being described in full in one of the papers comprising the monograph. C. C. Kiess and C. J. Humphreys, in another contribution, utilize this calibration in making intensity measurements on the $b$ group of $\mathrm{MgI}$ in the green, on the $H$ and $K$ lines of $\mathrm{Ca} I I$ in the ultraviolet, and on the Balmer lines of hydrogen. As is well known, the intensity decrement along the 
Balmer series furnishes a means of discriminating between the various possible modes of excitation of the lines. From $\mathrm{H} \gamma$ to $\mathrm{H} \eta$ the observations agree best with the Pauli-Schrödinger formula, in which the excitation is assumed to be by direct absorption of radiation in the Lyman series; whereas from $\mathrm{H} \theta$ to $\mathrm{H} \varphi$, which is the limit of practicable measurements, the intensities follow closely the Menzel-Baker formula, in which the Balmer emission is assumed to be due to recombination of protons with electrons freed by photo-electric ionization of hydrogen atoms by radiation beyond the Lyman series limit.

The partial aecomplishment of a very different part of the programme is described by P. A. McNally in the fifth paper of the series. The proposal here was to make accurate determinations of the times of contact by taking 260 photographs of the crescent during the partial phases. Clouds interfered with the completion of this programme, only about one half of the exposures being recorded, and only very few of these were secured within a minute of the times of contact. Nevertheless, the number of pictures taken was much greater than in any previous eclipse, and the paper shows how the observations can be satisfactorily reduced, and gives in tabular form the derived systems of corrections to ephemeris mean anomalies of the sun and moon.

The programme proposed by E. O. Hulburt was to deduce, by means of measurements of the sky brightness during the eclipse, the temperature of the upper air immediately following its illumination by full sunlight. Illuminometer measurements of the zenith sky on days previous to the eclipse had shown that the temperature during morning and evening twilight was $218^{\circ} \pm 15^{\circ} \mathrm{K}$. for all altitudes between $20 \mathrm{~km}$. and $60 \mathrm{~km}$. Analysis of a few observations made during the first half of totality in an isolated patch of clear sky shows that, as was expected, the brightness at this early stage was due mainly to light scattered more than once by atmospheric particles in the umbra below $20 \mathrm{~km}$. After mid-totality the clouds closed again, and made illuminometer measurements useless, since there is obviously no point in determining the brightness of the lower sides of clouds, which will doubtless be illuminated mainly by the horizon glow.

In the seventh and last paper of the monograph, T. R. Gilliland describes the radio observations, which were made for the purpose of studying the changes of ion density produced by the optical eclipse in the ionosphere. A self-contained trailer unit comprising a variable-frequency transmitter and receiver and a recording oscillograph was used at the eclipse site to record critical frequencies for the layers $E, F_{1}$ and $F_{2}$ at quarter-hour intervals on several control days before and after October 1, and at minute intervals during the eclipse. Unfortunately, a breakdown in one of the tuning condensers interrupted all recording shortly after third contact, and it was not resumed until after the eclipse ended. However, much of interest emerges from the ion densities deduced from the observed critical frequencies. In the layers $E$ and $F_{1}$ the ionization decreased to 22 per cent of its normal value within a minute or so of second contact, whereas the $F_{2}$ ion density was still dropping at third contact and probably reached a minimum of about 50 per cent of normal about an hour after the eclipse maximum. A puzzling feature of the observations is that the recombination coefficient estimated for the $E$ and $F_{1}$ layers depends somewhat on whether the depth of minimum or the time of minimum is considered; and a marked rise in the ion density two or three minutes before totality ended is also unexplained. The observations confirm the importance of the part played by solar dis. turbances in causing upper-air ionization : a distinct decrease in ion density occurred as the moon obscured a large sunspot.

Astronomers and physicists will sympathize with the members of the expedition in their bad luck with the weather, and will congratulate them on making such good use of the observational material they did manage to secure in spite of adverse circumstances.

\section{A. HuNTER.}

\section{HENRY FAIRFIELD OSBORN AND THE AMERICAN MUSEUM OF NATURAL HISTORY}

\author{
By Prof. W. K. GREGORY
}

N April 8 the double event of unveiling a bust of the late Prof. Henry Fairfield Osborn and the opening of the new North American Mammal Hall took place at the American Musoum of Natural History on the occasion of the annual members day. Mr. A. Perry Osborn, acting president of the Museum, presided at the meeting. In his opening address $\mathrm{Mr}$. Osborn told the members of some of the effects of the War upon the Museum in the loss of men to the army and the reduced operating funds. He spoke also of the assistance the Museum had been able to give to the Government by supplying information on the geography, climate, native diseases, and so forth, of the countries to which the American armies are likely to be assigned. He then introduced to the members Dr. A. E. Parr, who succeeds Dr. Roy C. Andrews as director of the Museum.

Before the uncovering of the memorial bust, Prof. William K. Gregory made a commemorative address on "Osborn, the Scientist", of which the following is the substance:

The unveiling of the bust of Henry Fairfield Osborn and the opening of the new Hall of North American Mammals are appropriately brought together in one meeting. To Osborn's enthusiasm and unconquerable energy we owe this entire memorial building, dedicated to his friend and fellow-naturalist, Theodore Roosevelt. This building in turn forms a perfect setting for the new hall, which is filled with superb mounts of the larger North American mammals in their native haunts-beloved alike by Roosevelt and Osborn.

Osborn's scientific studies on fossil mammals began in 1877, when he and several of his classmates at Princeton, including his close friend and colleague, William Berryman Scott, made their first expedition to the Bridger Eocene basin of Wyoming. Here they discovered enough strange extinct forms of mammalian life to give them an uncontrollable urge to discover more. From this expedition sprang a long and ever-branching system of explorations, at Princeton under Scott and at the American Museum under Osborn. From the Flaming Cliffs of the Gobi Desert and the withering slopes of the Siwaliks in India, to the frozen soil of Alaska, many a "valley of dry bones" has heard the clang of the explorer's pick and yielded up its dead. Under the spell of the prophet the dry bones came together and thus it happened 